\title{
Prediction of the Risk of Lymph Node Metastases in Early Gastric Cancer: Contrast-Enhanced Harmonic Endoscopic Ultrasonography May Help
}

\author{
Chiara Pierantoni, Andrea Lisotti, and Pietro Fusaroli \\ Gastroenterology Unit, Department of Medical and Surgical Sciences, Hospital of Imola, University of Bologna, Imola, Italy
}

\section{Article Info}

Received March 17, 2021

Accepted April 1, 2021

Published online June 22, 2021

\section{Corresponding Author}

Chiara Pierantoni

ORCID https://orcid.org/0000-0003-2160-5685

E-mail chiarapierantoni@gmail.com
To the Editor:

We have read with interest the article by Shin et al. ${ }^{1}$ reporting their experience in the evaluation of clinicopathologic features associated with lymph node metastases (LNM) in submucosal papillary gastric cancer.

The authors found that the LNM rate tended to be higher in papillary early gastric cancer (P-EGC) than in other differentiated types of EGC and that the rate increased to $25.6 \%$ when there was invasion of the submucosal layer.

Lymphovascular invasion was the only factor significantly associated with LNM in submucosal P-EGC. Moreover, location in the lower third of the stomach and elevated gross appearance were independent factors associated with lymphovascular invasion in submucosal P-EGC. Conversely, the depth of submucosal invasion, which is a known predictive factor against LNM in classic EGC, was not significantly associated with LNM.

These findings raise concern about the appropriateness of the current European guidelines that recommend the use of the same criteria for endoscopic submucosal dissection (ESD) as a treatment or both P-EGC and other differentiated EGCs. ${ }^{2}$ The feasibility of ESD for P-EGC is still debatable, in particular when it meets the expanded criteria.

Accurate assessment of the depth of invasion of EGC is critical for selecting the appropriate treatment option. Although endoscopic ultrasonography (EUS) has become the preferred tool for the locoregional staging of gastric cancer, ${ }^{3}$ there is no consensus on the accuracy of EUS for the evaluation of the invasion depth of EGC. ${ }^{4-6}$

However, several studies have shown the optimal accuracy of contrast-enhanced harmonic EUS (CH-EUS) for the differential diagnosis of benign and malignant lesions. ${ }^{7-10}$ In particular, the diagnostic accuracy of CH-EUS in the differential diagnosis of lymph nodes was comparable to those of EUS elastography and EUS-guided fine needle aspiration. ${ }^{11}$ Therefore, the characterization of lymph nodes could represent the main target of EUS during EGC staging rather than the T parameter, especially for PEGC.

Several studies performed on surgical specimens reported a worse prognosis associated with P-EGC than with other differentiated types. ${ }^{2,12}$ However, the treatment outcomes of ESD for P-EGC have not been precisely documented. ${ }^{12}$

A recent Korean study ${ }^{13}$ evaluated the short- and long-term outcomes after ESD in P-EGC; the curative resection rate of P-ECG was significantly lower than those of well differentiated and moderately differentiated EGC ( $49.4 \%$ vs $72.5 \%$ and $93.7 \%$, respectively), although it increased to $72.5 \%$ for mucosal (T1a) cancer. Despite the poor short-term outcomes, the long-term outcomes of ESD for P-EGC were favorable once 
curative resection was achieved (no LNM, no extragastric recurrences and a low metachronous recurrence).

As discussed by the authors, qualitative endoscopic criteria evaluation and accurate staging should be adopted for the assessment of submucosal invasive P-EGC, although lymphovascular invasion is difficult to predict. Indeed, accurate staging, together with a radical endoscopic or surgical resection of gastric neoplasia can significantly improve patients' clinical outcomes. ${ }^{14}$

In P-EGC accurate $\mathrm{N}$ staging is crucial due to the high rate of LNM even in the early stages. We think that EUS evaluation, together with $\mathrm{CH}$-EUS, should therefore be included in the staging process for P-EGC. Further largescale studies are needed to demonstrate whether the correct staging yield and prediction of lymphovascular invasion could be further improved.

\section{CONFLICTS OF INTEREST}

No potential conflict of interest relevant to this article was reported.

\section{ORCID}

Chiara Pierantoni https://orcid.org/0000-0003-2160-5685

Andrea Lisotti https://orcid.org/0000-0002-7724-7402

Pietro Fusaroli https://orcid.org/0000-0002-4397-9314

\section{REFERENCES}

1. Shin SY, Kim JH, Kook MC, et al. Clinicopathologic features of submucosal papillary gastric cancer differ from those of other differentiated-type histologies. Gut Liver 2021;15:4452.

2. Lee HJ, Kim GH, Park DY, et al. Endoscopic submucosal dissection for papillary adenocarcinoma of the stomach: is it really safe? Gastric Cancer 2017;20:978-986.

3. Caletti G, Fusaroli P. The rediscovery of endoscopic ultrasound (EUS) in gastric cancer staging. Endoscopy 2012;44:553-555.
4. Shi D, Xi XX. Factors affecting the accuracy of endoscopic ultrasonography in the diagnosis of early gastric cancer invasion depth: a meta-analysis. Gastroenterol Res Pract 2019;2019:8241381.

5. Fusaroli P, Kypraios D, Eloubeidi MA, Caletti G. Levels of evidence in endoscopic ultrasonography: a systematic review. Dig Dis Sci 2012;57:602-609.

6. Pei Q, Wang L, Pan J, Ling T, Lv Y, Zou X. Endoscopic ultrasonography for staging depth of invasion in early gastric cancer: a meta-analysis. J Gastroenterol Hepatol 2015;30:15661573.

7. Fusaroli P, D’Ercole MC, De Giorgio R, Serrani M, Caletti G. Contrast harmonic endoscopic ultrasonography in the characterization of pancreatic metastases (with video). Pancreas 2014;43:584-587.

8. Yamashita Y, Shimokawa T, Napoléon B, et al. Value of contrast-enhanced harmonic endoscopic ultrasonography with enhancement pattern for diagnosis of pancreatic cancer: a meta-analysis. Dig Endosc 2019;31:125-133.

9. Kamata K, Takenaka M, Kitano M, et al. Contrast-enhanced harmonic endoscopic ultrasonography for differential diagnosis of localized gallbladder lesions. Dig Endosc 2018;30:98-106.

10. Kamata K, Takenaka M, Kitano M, et al. Contrast-enhanced harmonic endoscopic ultrasonography for differential diagnosis of submucosal tumors of the upper gastrointestinal tract. J Gastroenterol Hepatol 2017;32:1686-1692.

11. Lisotti A, Ricci C, Serrani M, et al. Contrast-enhanced endoscopic ultrasound for the differential diagnosis between benign and malignant lymph nodes: a meta-analysis. Endosc Int Open 2019;7:E504-E513.

12. Bang CS, Lee JJ, Baik GH. Endoscopic submucosal dissection of papillary gastric adenocarcinoma; systematic review. J Clin Med 2020;9:1465.

13. Kim TS, Min BH, Kim KM, Lee JH, Rhee PL, Kim JJ. Endoscopic submucosal dissection for papillary adenocarcinoma of the stomach: low curative resection rate but favorable long-term outcomes after curative resection. Gastric Cancer 2019;22:363-368.

14. Catena F, Di Battista M, Ansaloni L, et al. Microscopic margins of resection influence primary gastrointestinal stromal tumor survival. Onkologie 2012;35:645-648. 